FOLIA SCANDINAVICA VOL. 25 POZNAŃ 2018 DOI: $10.2478 /$ fsp-2018-0010

\title{
LINGUISTICS
}

\section{INDIREKTA ANAFORER I INLÄRAR- SVENSKA: ANALYS AV KORTA TEXTER SKRIVNA AV SVENSKSTUDERANDE I POLEN}

NATALIA KOŁACZEK

Adam Mickiewicz University in Poznań

ABSTRaCT. Definiteness appears to be one of the most difficult categories for learners of Swedish. Particularly difficult are the socalled indirect anaphors, definite noun phrases without any explicit antecedent in text. The choice of a definite noun phrase in such contexts requires language skills on a higher level and even some general knowledge about the world. Such phrases make a very nuanced category, yet they are marginalised in textbooks for learning Swedish. This paper presents the results of a study conducted among a group of Polish students of Swedish at the Adam Mickiewicz University in Poznań. The analysis considers noun phrases used in contexts for indirect and direct anaphors excerpted from short texts written by the students based on a picture story. The results reveal that the students' use of indirect anaphors is not stable. It can be assumed that indirect anaphors concerning body parts are easier to acquire for the learners. Another important factor is the relation of possession between anaphors and triggers. Students often omit the suffixed definite article in context for both indirect and direct anaphors. The study is included in my doctoral thesis written on this topic.

\section{INLEDNING}

Kategorin species framstår som svår för inlärare av svenska. Detta påstås av forskare, lärare och inlärare av svenska själva (jfr Kowal 2011:100, Nyqvist 2016:306ff., Ekerot 2011:9, 166, Szulc 1992:53, Dabrowska 2015:31, Engström 2011:13f., 22). Behärskning av regler som styr över det svenska speciessystemet kräver kunskaper som gäller den morfologiska, syntaktiska och pragmatiska nivån (Eriksson \& Wijk-Andersson 1988:1) och omfattar 
flera områden: betydelse, form och även relationen mellan dem. Detta förhållande är emellertid inte bara komplext utan till och med "inte till fullo utrett" (Bolander 2001:98). Species är dessutom en obligatorisk kategori i svenskan, vilket kan bidra till svårighetsnivån för de inlärare vars modersmål saknar morfologisk markering av bestämdhet, som till exempel polskan.

Som särskilt svårt framstår bruket av substantivets bestämda form som i litteraturen betecknas med olika termer, bland annat: implicit bestämdhet (Ekerot 2011), indirekt anafor (Schwarz 2000) eller first-mention uses (Fraurud 1990:401). Dessa begrepp omfattar fraser som används "när man refererar till något som är en del av eller ses som självklart attribut till något" (Ekerot 2011:145) och som i motsats till direkta anaforer inte har någon explicit antecedent utan står i en relation till ett element i texten (trigger) som möjliggör dess tolkning (Schwarz 2000:1, 48ff.), som i Ingen bil är så bra att motorn håller $i$ evighet, där frasen ingen bil fungerar som trigger för frasen motorn, dvs. bilens motor, bilens självklara attribut (SAG 3 1999:166). Fler exempel diskuteras i avsnitt 2.1.

Sådana fraser är marginaliserade i undervisningen där regeln om "det andra omnämnandet" till största delen betraktas som ett mönsterfall, medan användning av samma substantiv (som i Jag såg en hund. Hunden var stor) egentligen inte är vanlig i den naturliga kommunikationen (Nyqvist 2013b, Svartholm 1978:28). Val av rätt form i kontexter för indirekta anaforer kräver överföring av information över sats- och meningsgränser: "har man tidigare i samma diskussion talat om ett bröllop, används bestämd form av t.ex. bruden respektive brudgummen flera meningar senare, även om dessa inte omtalats tidigare" (Nyqvist 2013a:36), vilket behärskas av inlärare först på högre färdighetsnivåer (Nyqvist 2013a:61f.). Indirekta anaforer framstår dessutom som en nyanserad kategori och vissa typer av bruk är lättare för språkinlärare än andra (Kołaczek 2017b:40f.).

Undersökningen som presenteras i föreliggande artikel ingår i min doktorsavhandling. Syftet med artikeln är att svara på följande undersökningsfrågor:

- Vilka typer av nominalfraser väljs av inlärarna i kontexter för indirekta anaforer?

- I vilka kontexter undviker inlärarna substantiv med den bestämda artikeln och föredrar andra typer av definita nominalfraser, till exempel fraser med possessiva pronomen?

- Vilken påverkan har relationer mellan anaforer och deras trigger på anaforers svårighetsnivå sedd ur språkinlärningsperspektiv?

Svar på dessa frågor söks med utgångspunkt i typologier över indirekta anaforer som redan har beskrivits i litteraturen kring detta ämne.

Artikeln har följande struktur: först presenteras konceptet av indirekta anaforer. Sedan diskuteras fenomenet ur inlärningsperspektiv. I 3 redogörs det för studiens material, informantgrupper och metod och studiens resultat presenteras och diskuteras i 4 och 5 . 


\section{INDIREKTA ANAFORER}

\subsection{BEGREPPET INDIREKT ANAFOR OCH KLASSIFIKATIONER}

\section{AV INDIREKTA ANAFORER}

Med begreppet indirekta anaforer menas i föreliggande artikel definita nominalfraser som inte har någon explicit antecedent (detta skiljer dem från direkta anaforer). Det kan däremot identifieras ett element i texten som står i relation med anaforen och gör dess tolkning möjlig (Schwarz 2000:1, 48ff., Consten 2004:67ff., Irmer 2011:223). Detta innebär att indirekta anaforer "betecknar någon eller något som kan identifieras därför att det står i unik relation till något som redan etablerats i det textuella rummet" (SAG 3 1999:156). På så sätt påminner Schwarz definition om Hawkins (1978) associative anaphoric use av den icke-generiska definita artikeln och Ekerots (2011) implicit bestämdhet, alltså man refererar till något som uppfattas som en framträdande, frekvent och mer eller mindre obligatorisk komponent eller ett attribut av ett annat element $i$ texten:

(1) I went to a wedding last weekend. The bride was a friend of mine. She baked the cake herself.

(2) Förlåt min sena ankomst, men bilen krånglade.

Ur studien exkluderas alltså ytterligare uttryck som hos andra forskare (jfr Asher \& Lascarides 1998:83f., Imrer 2011:225, Schwarz 2000:67, Clark 1983:418, SAG 3 199:166) räknas som indirekta anaforer, såsom indefinita nominalfraser, pronomen eller strukturer som motsvarar det-utbrytningar (eng. it-cleft):

(3) Jack was going to commit suicide. He got a rope.

(4) Nu har familjen flyttat. Han har visst fătt ett jobb uppåt landet.

(5) In the group there was one person missing. It was Mary who left.

Sådana antecedentlösa definita fraser betecknas i litteraturen också med andra termer, såsom inferrables (Prince 1981), first-mention definites (Fraurud 1990) eller bridges (Clark 1983, Asher \& Lascarides 1998, Gardent et al. 2003).

I min studie analyseras informanternas formval i kontexter för indirekta anaforer i texter som de producerade själva. Till skillnad från Frauruds (1990) och Schwarz (2000) studier används därför i artikeln begreppet trigger (Hawkins 1978) istället för anchor/Anker för att beskriva det element i texten som står i relation till anaforen. Informanternas uppgift är ju inte att söka potentiella "förankringar" i färdigskrivna texter, utan informanterna själva 
aktiverar olika associationer i sin egen produktion. På så sätt kan de känna igen indirekt anaforiska nominalfraser och använda substantiv i bestämd form.

Trots att indirekta anaforer utgör en nyanserad och mångfacetterad kategori, betraktas de ofta som en homogen grupp (bl.a. Hawkins 1978, Prince 1981, Fraurud 1990) och försök till deras djupare klassificering är relativt fåtaliga (Clark 1983, Schwarz 2000, Gardent et al. 2003). Förslag på typologier som hittas hos Schwarz (2000) och Gardent et al. (2003) är tillräckligt omfattande och detaljerade och därför utgör de utgångspunkten för analyser i denna studie.

Schwarz (2000, Schwarz-Friesel 2007) skriver om i princip två huvudtyper av indirekta anaforer: semantiskt och konceptuellt baserade. Tolkning av de semantiskt baserade indirekta anaforerna utgår ifrån lexikaliska kunskaper medan de konceptuellt baserade indirekta anaforerna kräver kunskap om omvärlden. De två huvudtyperna delas vidare in i ytterligare undertyper som diskuteras nedan. De illustreras med exempel 6-9, där meningarna markerade med (a) hämtats ur Schwarz (2000, Schwarz-Friesel 2007) och de svenska exemplen kommer från SAG 3 (1999) eller svenska tidningstexter samlade av Kołaczek (2017b).

Indirekta anaforer av den meronymiska semantiska typen presenteras ofta som de mest typiska och mest frekventa. De avser sådana fall där den indirekta anaforen är en del av anaforens trigger.

(6a) Nimm nicht die gelbe Tasse. Da ist der Henkel kaputt.

(6b) Hon köpte ett rokokobord. Ett av benen var skadad.

Indirekta anaforer av den lexikaliska/tematiska semantiska typen uttrycker verbsemantiska tematiska roller, t.ex. instrument, agens, patiens eller objekt:

(7a) Ich wollte rasch die Haustür aufschließen, weil ich das Telefon klingeln hörte. Der Schlüssel war aber tief unten im Einkaufswagen vergraben.

(7b) Kvinnan mördades och polisen beslagtog hennes arbetstelefon och dator. [...] Anna Lith förklarar att hon inte har något annat intresse än att mördaren ska fällas.

Schemabaserade konceptuella indirekta anaforer tolkas inte genom semantiska relationer, utan anaforens trigger aktiverar ett "mentalt schema" som omfattar olika associationer och sammankopplingar:

(8a) Ich kenne ein schönes Restaurant in Refrath. Das Essen ist köstlich, und der Kellner ganz besonders nett.

(8b) Utvisningen i tisdags ska ha gått lugnt till fram till att de kommit ombord flygplanet [...]. - Han ville prata med kaptenen och inte sitta still [...]. Då ska kabinpersonalen ha blivit orolig för att genomföra flygningen med mannen ombord $[\ldots]$. 
Inferensbaserade konceptuella indirekta anaforer uttrycker mycket mer komplicerade relationer mellan anaforer och dess triggers. De överskrider standardscheman och därför baseras på slutledningar:

(9a) Zahnarzt Dr. Meyers hat schon längere Zeit ein Verhältnis mit der Sprechstundenhilfe. Als seine Frau im Auto verbrennt, spricht Meyer von Unfall. Die Gutachter vermuten anders.

(9b) Hantverkarna gjorde ett uselt jobb - och pressade sedan den äldre mannen från Partille att betala en halv miljon kronor. Nu utreds fallet av polisen. [...] Hantverkarna började mer eller mindre på eget bevåg göra jobb på såväl taket som fasaden.

Eftersom man kan urskilja flera blandade typer och gränsfall (Schwarz 2000:99) presenterar Schwarz sin typologi snarare som ett kontinuum, en skala utbredd mellan tydligt semantiska till tydligt inferentiella typer, med konceptuella typer och olika blandtyper däremellan.

Gardents et al. (2003) typologi över bridging-relationer utgår ifrån relationer mellan anaforer och triggers. De skiljer mellan följande typer: set membership (baserad på inklusion, med källan i hyponymi, t.ex. seminars/the last seminar, the army/the third), thematic roles (baserad på tematiska roll, med källan i semantiska rolluppsättningar, t.ex. murder/the murderer), definitional (med källan i lexikografiska definitioner eller meronymi, t.ex. operation/ convalescence), co-participants (med källan i lexikografiska definitioner av både anaforen och trigger, t.ex. trip/seat) och non-lexical (med källan som överskrider lexikala kunskaper, såsom diskursstrukturen eller kunskap om omvärlden, t.ex. laguna/the inhabitants, fight/dead). Denna typologi använder jag som komplettering till Schwarz modell.

\subsection{INDIREKTA ANAFORER I SVENSKAN UR INLÄRNINGSPERSPEKTIV}

Att titta på indirekta anaforer med språkinlärning som utgångspunkt är ett nytt betraktelsesätt som kan ge nya insikter, inte bara ur det didaktiska perspektivet utan också ur den teoretiska synvinkeln, nämligen angående djupare beskrivning av denna kategori.

Indirekta anaforer har hittills blivit till forskningsobjekt i bland annat psykologiska studier (bl.a. Clark 1983), korpusbaserade studier kring bruk av definita fraser (bl.a. Hawkins 1978, Fraurud 1990, Poesio \& Vieira 1998, Gardent et al. 2003), pragmatiska och kognitiva studier (bl.a. Prince 1981, Löbner 1998, Schwarz 2000, Matsui 2000) eller formella redovisningar (bl.a. Asher \& Lascarides 1998) (jfr genomgångar hos Irmer 2011:223f. och Zhao 2014:130ff.). Det som oftast tas upp är analyser av anaforens roll i diskursen, processer av dess tolkning och sökning efter triggers. Alla sådana studier behandlar ju förstaspråksperspektiv. 
A andra sidan kan man observera att de viktigaste studierna kring inlärning av bestämdhet hos andraspråksinlärare (Eriksson \& Wijk-Andersson 1988, Axelsson 1994, Nyqvist 2013a) snarare fokuserar på utveckling av formbildningen än på formvalet. Till Erikssons \& Wijk-Anderssons (1988) resultat hör bland annat att deras polska informanter underanvände såväl framförställda obestämda artiklar som bestämda slutartiklar och hade en tendens att använda pronomen istället för artiklar. Axelsson (1994) formulerar en svårighetshierarki för utveckling av olika typer av fraser (t.ex. substantiv med bestämdhetssuffix, artikellösa substantiv med attribut, substantiv med bestämdhetssuffix, framförställd bestämd artikel och attribut, substantiv i naken form, substantiv med framförställd obestämd artikel, substantiv med framförställd obestämd artikel och attribut m.m.) baserad på data från inlärare av svenska med finska, polska och spanska som modersmål. Nyqvists (2013a) studie fokuserar på finska inlärare av svenska och hennes centrala resultat gäller huvudsakligen utveckling av korrekthetsprocenten för olika typer av fraser (nakna substantiv, obestämd och bestämd form singularis och pluralis, fraser med possessivattribut).

Indirekta anaforer marginaliseras dessutom i läromaterial i svenska för nybörjare. Nyqvist (2013b) kritiserar finska läroboksserier och skriver att "övningarna är mekaniska och upprepar regeln om »det andra omnämnandet«". Det finns ju empiriska belägg på att "det första omnämnandet" inte är sekundärt, utan utgör det mest frekventa bruket av definita nominalfraser i svenskan (Fraurud 1990:405). Mina analyser av svenska läroböcker för nybörjare som används på Institutionen för skandinavistik vid Adam Mickiewiczuniversitetet i Poznań (Kołaczek 2017a) är liknande: såväl presentationen av regler för kategorin bestämdhet som övningarna gäller först och främst formbildningen medan regler för formvalet sällan förklaras. Mycket plats i läromaterialen tar direkta anaforer och "det andra omnämnandet". Implicit bestämdhet presenteras indirekt när ämnet hälsan diskuteras och då ges det flera exempel på uttryck med kroppsdelar. Andra kontexter förutom de meronymiska är svåra att spåra.

\section{MATERIAL OCH METOD}

Undersökningen som presenteras i artikeln omfattar korta texter skrivna av en grupp av studenter vid ett enstaka tillfälle. Informantgruppen bestod av 10 studenter från årskurs 2 i svensk filologi (kandidatstudier) på Institutionen för skandinavistik vid Adam Mickiewicz-universitetet i Poznań. Undersökningen genomfördes under lektionstid på vårterminen läsåret 2014/2015. Studenterna på institutionen förväntas ha nått nivå A1 i svenska efter årskurs 1 och nivå A2 efter årskurs 2. Gruppen karakteriseras av stor homogenitet. Studenterna är i liknande ålder och har polska som modersmål. De börjar läsa 
svenska som nybörjare utan några förkunskaper i detta språk. Alla kan däremot åtminstone ett annat språk: tyska eller engelska och deras nivå kan beskrivas som åtminstone "självständiga språkanvändare" (Gemensam europeisk referensram för språk 2007:23). Påverkan av tyska respektive engelska tematiseras inte $\mathrm{i}$ undersökningen, men det är viktigt att studenterna överhuvudtaget har allmän erfarenhet av främmandespråksinlärning (Hammarberg 2016:49ff.), i synnerhet av germanska språk som har artiklar, i motsats till den artikellösa polskan. Under studiernas gång har informanterna deltagit i samma kurser, vilket innebär att de undervisas av samma lärare och arbetar med samma kursmaterial. Alla de 10 informanterna är kvinnor.

Studenternas uppgift i undersökningen var att beskriva en tecknad historia (Orientación Andújar. Recursos Educativos u.å., se Fig.1). Den valdes med hänsyn till hur Schwarz (2000:111f., Schwarz-Friesel 2007:10) exemplifierar indirekta anaforer av den konceptuella typen. I denna typ aktiverar anaforens trigger ett "mentalt schema" som omfattar olika element. Till exempel restaurang som trigger aktiverar ett schema som innehåller sådana element som bl.a. servitör, mat, meny eller nota, som exempel 8a:

(8a) Ich kenne ein schönes Restaurant in Refrath. Das Essen ist köstlich, und der Kellner ganz besonders nett.
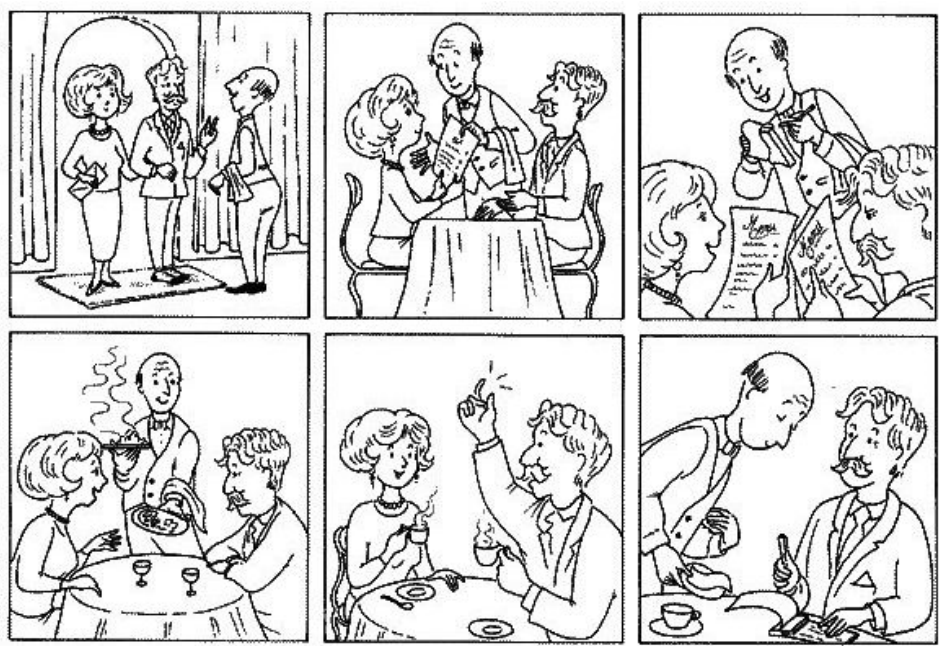

(Fig. 1) Tecknad historia ur Orientación Andújar. Recursos Educativos (u.å.).

Undersökningsbladen konstruerades så att varje enskild bild i den tecknade historian befann sig på en separat sida. Studenterna uppmärksammades att inte bläddra igenom hela historian, utan att beskriva bilderna en efter en, så detaljerat som möjligt. På så sätt fick informanterna ny information med nya 
bilder, vilket kan ha påverkat artikelbruket. Det var dessutom viktigt att studenterna själva ansvarade för texternas struktur, ord- och formvalet. Av detta skäl kan man förvänta sig att informanterna oftare valde strukturer som de själva trodde de hade behärskat. Texterna skrevs av studenterna anonymt, för analysens skull fick de beteckningar från I1 till I10 som tillskrevs i slumpmässig ordning.

De samlade texterna bestod i genomsnitt av 170 ord och innehöll igenomsnitt 41 nominalfraser. Alla exempel ur studenttexterna citeras i artikeln med deras originalstavning.

Analysen omfattade bara formvalet och inte formbildningen eller ordvalet. Detta innebär att formerna servitrösen (I1) eller servismannen (I3) analyserades på samma sätt som formen servitören (eller servitörn), formerna menün (I1), menju eller menu (I8) analyserades som menyn respektive meny och manen (I4) tolkades som mannen. Dessutom tolkades ordet tassar (I2) som koppar (som uppenbarligen förväxlades med det tyska ordet die Tasse). Analysen gick ut på att excerpera alla kontexter för indirekta anaforer och granska vilka fraser som används i dessa kontexter, jämför exempel 10 och 11:

(10) Paret beställer någonting [...] Servitör hämtar maten och ger den till gästerna. (I5)

(11) Manen och kvinnan säger vad vill de ha från menu. Den är kvinnan som säger först. Kvinnan är mycket glad när hon ser servitören med mat. (I4)

Substantiv med bestämd slutartikel, substantiv med possessiva pronomen och substantiv med framförställd bestämd artikel (exempel 12-14) betraktades som en kategori i analysen.

(12) Servitören ger mannen en check och han betalar inte med pengar. Han håller en penna i handen. (I2)

(13) Mannen och kvinnan pratar och skojar, mannen gör en ljud med sina fingrar. (I2)

(14) Mannen får notan och nu vill han betala för maten. Men nu ser han lite arg ut. Han har en penna i den ena handen och en chequebok i den andra. (I5)

För jämförelses skull excerperades kontexter för direkta anaforer på liknande sätt. Även för denna kategori användes samma principer angående vilka typer av fraser som samlades:

(15) En man kommer till en restaurangen med sin fru. [...] Manen och kvinna sitter vid bordet och servitörn tar han om de. (I4)

(16) Per och Frida Andersson är gifta med varandra redan 25 år. För att jubla går de på restaurang. En servitör tar dem emot och visar dem ett ledigt bord. [...] Den leende servitörn skriver ner deras beställning. (I6) 
Ett särskilt fall utgjorde texterna där informanterna valde att namnge gestalterna $\mathrm{i}$ historian. Om samma namn användes $\mathrm{i}$ texten, räknades sådant bruk också som direkt anafor:

(17) Fru Larsson kommer till en restaurang med sin man. Fru Larsson och hennes man har elleganta kläder på sig. (I9)

Denna kategori tillskrevs dessutom fall när koreferens inte bara uttrycktes med hjälp av samma substantiv:

(18) Frida bestämmer sig att ta lax med ris, Per beställer grillad kyckling med potatis. [...] Nu måste de vänta på sina rätter. (I6)

(19) Fru Larsson kommer till en restaurang med sin man. Herr Larsson säger till en servitör att de vill ha bordet för två. (19)

(20) På denna bild finns det tre personer. Man kan se en kvinna, hennes man och servitrös. [...] Paret tar på sig de fina kläderna. (I1)

Förutom kontexter för indirekta och direkta anaforer omfattar den kvalitativa analysen också exempel på överanvändning av substantivets bestämda form, alltså kontexter som uppenbarligen tolkades av studenterna som indirekta anaforer.

\section{RESULTAT}

Analysresultaten bekräftar att den tecknade historian, som var utgångspunkten för studenternas texter, påverkade förekomsten av kontexter för indirekta anaforer av den konceptuella typen. I all studenternas produktion noterades fraser som Schwarz själv presenterar som exempel på element i det konceptuella schemat, nämligen servitör, mat, meny eller nota. I artikeln redogör jag för alla exempel på indirekta anaforer som excerperades ur texterna.

Prepositionsfrasen vid bordet noterades i kontexter för indirekt anafor i 5 av alla 10 texter (exempel 21-25), medan i de övriga 5 texterna användes substantivet bord i direkt anaforisk betydelse (med bestämd slutartikel, som i exempel 26), i specifik indefinit betydelse (med framförställd obestämd artikel, som exempel 27), eller det nämndes inga bord alls.

(21) På denna bild finns det tre personer [...] De befinner sig på en restaurant [...] Paret sitter vid bordet och beställer maten. (I1)

(22) Det finns en kvinna och en man som gick in i restaurangen. [...] Kvinnan och mannen sitter vid bordet och servitören ger henne en meny. (I2)

(23) Manen och kvinna sitter vid bordet och servitören tar han om de. (I4)

(24) Det paret sitter vid bordet. (I5) 
(25) Servitören försöker att hjälpa henne att välja mat. De sitter vid bordet. (I7)

(26) En servitör tar dem emot och visar dem ett ledigt bord. De sätter sig vid bordet. (I6)

(27) Paret sitter runt omkring ett bord. (I10)

Substantivet bordet i sin bestämda form överanvändes dessutom av en informant som övertolkade dess relation till restaurang-schemat medan frasen användes i icke-specifik indefinit kontext:

(28) Herr Larsson säger till en servitör att de vill ha bordet för två. (I9)

Meny är ett annat typiskt element av restaurang-schemat. Det förekom frekvent också i studenttexterna men bara en student använde substantivet med bestämd slutartikel:

(29) Servitören erbjuder till dem olika maträtter och visar menün. (I1)

Tre informanter valde frasen med framförställd obestämd artikel, en meny. Man kan tolka det så att de snarare uppfattade meny som ett av flera exemplar av matsedlar som samtidigt kan användas av olika restauranggäster, till exempel:

(30) Kvinnan och mannen sitter vid bordet och servitören ger henne en meny. (I2)

Majoriteten, det vill säga 6 av 10 informanter, valde däremot substantivet i naken form. Fraserna räknades som kontexter för indirekt anafor som inte igenkändes av informanterna:

(31) Servitören är tillbaka. Manen och kvinnan säger vad vill de ha från menu. (I4)

(32) En servitör säger vad är på menu och vad han rekommendera. (I5)

(33) Kvinnan tittar på menu och funderar över vad det är som har en lust att äta. (I7)

(34) Påret sitter vid bordet och servitören visar de menju. (I8)

(35) De sitter vid bordet och får menu. (I9)

(36) Servitören visar kvinnan meny. (I10)

Informanterna hade däremot inte större problem med att igenkänna den indirekt anaforiska kontexten när det gällde substantivet mat. Det användes av informanterna ofta just med bestämd slutartikel:

(37) Paret sitter vid bordet och beställer maten. (I1)

(38) De väljer rätter från menyn och ser glada ut. Servitören skriver vad de beställer. Servitören kommer med maten som är het. (I2) 
(39) Paret beställer någonting. [...] Servitör hämtar maten och ger den till gästerna. (I5)

(40) Servitören antecknar deras val och rekommenderar vin till maten. (I8)

(41) Paret sitter och pratar medan servitören bringar deras mat. (I10)

En av studenterna använde sig av liknande struktur men hon kände inte igen den som kontext för det indirekt anaforiska bruket av bestämd slutartikel utan valde substantivets nakna form:

(42) Manen och kvinnan säger vad vill de ha från menu. Den är kvinnan som säger först. Kvinnan är mycket glad när hon ser servitören med mat. (I4)

Ett annat prototypiskt exempel som nämns av Schwarz är nota. Substantiven nota, kvitto och räkning noterades i texter skrivna av 8 informanter, och då användes de med bestämd slutartikel av 5 informanter. Man kan dock anta att studenternas val påverkades av att fraserna kunde ha lärts in som helheter i dialoger som äger rum på restaurang. De tränas i undervisningen, till exempel i sekvenserna som: Kan jag få notan?, Kan vi be om notan? eller även Notan, tack!.

(43) Efter kvällsmaten sitter de vid bordet fortfarande och dricker en kopp kaffe. Maken ropar på servitrösen eftersom han vill betala notan. (I1)

(44) Paret dricker kaffe och mannen vill kalla efter servitören. Naturligtvis vill kan få notan och de vill åka hem. (I5)

(45) Trots att de har det bra, kommer de överens att det är högsta tid för att gå hem. Det är redan sen. Per anropar servitören och ber om notan. (I6)

(46) Mannen vill betala för maten (som en riktig gentleman) och klickar med fingrarna efter servitören. Servitören kommer med kvittot och mannen betalar med check. (I8)

(47) Paret dricker kaffe. Mannen utmärker att han vill betala. Servitören bringar kvittot och mannen skriver en check. (I10)

De ovannämnda substantiven användes av andra informanter i motsvarande strukturer, men då med framförställd obestämd artikel:

(48) Mannen visar med handen att servismannen ska komma till honom med ett kvitto. (I3)

(49) Manen kallar för servitören eftersom han ville få ett kvitto. (I4)

(50) När de har ätit, bestämde de sig för att ta en kopp kaffe. Mannen vill kanske betala en räkning och han använder sina fingrarna för att sygnalisera det till servitörn. (I7)

Indirekta anaforer av den konceptuella typen angick inte bara restaurangschemat. Det hittades ett exempel på indirekt anafor av denna typ som baserades på ett schema angående kortbetalning: 
(51) Han betalar med en bankkort och knappar in koden. (I7)

Trots att undersökningen utgick ifrån fokus på indirekta anaforer av den konceptuella typen, hittades ett större antal exempel på indirekta anaforer av den semantiska typen i studenttexterna. Det visade sig nämligen att informanterna inte bara koncentrerade sig på att beskriva vad som hände på restaurangen utan de beskrev också karakterärna själva och hänvisade till deras utseende, gester och mimik. Fraser som refererade till kroppsdelar, alltså särskilda fall för meronymer, förekom i studenttexterna antingen som substantiv med bestämd slutartikel (t.ex. fingrarna) eller substantiv med fraser med possessiva pronomen (t.ex. sina fingrar). Ekerot $(2011: 147,155)$ pekar på att ett possessivuttryck är ett alternativ till implicit bestämdhet, medan engelskan "måste ha possessivuttryck vid kroppsdelar" i motsats till svenskan (t.ex. My feet hurt). Man kan alltså anta att studenternas val kan ha påverkats av deras kunskaper i engelska.

(52) Mannen vill betala för maten [...] och klickar med fingrarna. (I8)

(53) Mannen och kvinnan pratar och skojar, mannen gör en ljud med sina fingrar. (I2)

(54) Mannen vill kanske betala en räkning och han använder sina fingrarna för att sygnalisera det till servitörn. (I7)

(55) Kvinnan håller en handväska i handen. (I2)

(56) De har klart sin lunch. De ser glada ut. Mannen visar med handen att servismannen ska komma till honom med ett kvitto. (I3)

(57) Servitören ger mannen en check och han betalar inte med pengar. Han håller en penna i handen. (I2)

(58) Mannen får notan och nu vill han betala för maten. [...] Han har en penna i den ena handen och en chequebok i den andra. (I5)

(59) Servitör har något hängande på armen. (I2)

(60) En av männen ser ut som servitör för en handduk hänger över hans arm. (I10)

(61) Han kanske har fått lite pengar eftersom har vår så hjälpsam och alltid med leende på läpparna. (I8)

(62) Mannen ser så snyggt ut med sin stor mustasch [...]. (I8)

Ur en tvärsnittsstudie som genomfördes på Institutionen för skandinavistik tidigare samma år framgår att relationen av ägande och tillhörande spelar en stor roll för studenternas val av definita nominalfraser (Kołaczek 2017b:36). Denna relation mellan olika element $i$ texten användes mycket frekvent som motivering för informanternas val av substantivets bestämda form i en lucktext, även om formen skilde sig från originaltexten. Denna påverkan är synlig också i texterna som studenterna skrev själva. Det excerperades fraser som refererar till karaktärernas attribut eller andra fenomen som tillhör karaktärerna 
och då handlade det om substantiv med bestämd slutartikel eller substantiv med possessiva pronomen (som ett alternativ till substantivets bestämda form):

(63) Servitören skriver på papret en beställning. (I1)

(64) De säger till servitören vad de vill äta till servitören och han skriver allt på pappret. (I5)

(65) Kvinnan och den annan mannen ser ut som ett rikt, elegant, även aristokratiskt par på grund av deras fina kläder. (I10)

(66) Servitören ser så jävla [sic!] glad ut (han kanske älskar sitt arbete). (I8)

Liknande fraser excerperades dessutom ur två ytterligare texter (exempel 67 och 68) där de användes i kontexter för specifik indefinit betydelse. Informanternas val betraktas därför som avvikande.

(67) De befinner sig på en restaurant. Servitrösen hälsar på detta par. Paret tar [har] på sig de fina kläderna. (I1)

(68) Paret har kommit in och servismannen hälsar på dem. Paret har eleganta kläderna på sig så det kanske är en restaurang. (I3)

I det samlade materialet hittades också exempel på indirekta anaforer med verbala triggers (exempel 69-72). Några par av anaforer och triggers var till och med kognater (exempel 70 och 71). Denna relation igenkändes inte av alla informanter som använde sig av liknande strukturer men med annan typ av fras (exempel 72).

(69) Mannen och kvinnan tittar på menyer och bestämmer vad som de vill ha. Servitören antecknar deras val. (I10)

(70) Både kvinnan och mannen vet vad ska de välja ut menju. Servitören antecknar deras valj och rekommenderar vin till maten. (I8)

(71) Frida bestämmer sig att ta lax med ris. Per beställer grillad kyckling med potatis. Den leende servitörn skriver ner deras beställning. (I6)

(72) Paret läser noggrant menün och beställer någonting smakrikt. Servitören skriver på papret en beställning. (I1)

Ur materialet excerperades dessutom ett exempel som inte riktigt kan tillskrivas de tidigare beskrivna grupperna. Användning av bestämd form kopparna i exempel 73 skulle förklaras här med att det ingår i ett kaffefats definition att det fungerar som ett underlag för en kaffekopp (jfr Gardents et al. 2003 definitional typ av bridging). Relationen mellan kaffefat och koppar kändes ändå inte igen av informanten som kontext för indirekt anaforiskt bruk av substantivets bestämda form.

(73) På bordet ligger två kaffeefater och de dricker kaffee från tassar [koppar]. (I2) 
Middagen och kvällsmaten i exempel 74-76 kan inte tolkas som element av det konceptuella restaurang-schemat på samma sätt som till exempel servitörer eller menyer, trots att de påminner om frasen maten i exempel 37-40. De kan snarare noteras som indirekta anaforer av den inferentiella typen. I studenternas texter handlar det nämligen inte om maten i den konkreta betydelsen (då borde middagen och kvällsmaten uppfattas som exempel på direkt anafor) utan snarare om deras mer abstrakta betydelse, som måltider eller som själva aktiviteten av middagsätandet respektive kvällsmatsätandet. Dessa exempel tillhör då anaforer av den inferentiella typen. Exempel 77 visar en parallell struktur som uppfattas som avvikande på grund av bortfall av artikel.

(74) Efter middagen dricker de kaffe. (I9)

(75) Efter den goda middag dricker de kaffe. (I6)

(76) Efter kvällsmaten sitter de vid bordet fortfarande och dricker en kopp kaffe. (I1)

(77) Efter middag manen vill betala. (I4)

\section{DISKUSSION}

Det framgår av analysen av de excerperade fragmenten att inte bara indirekta anaforer förekom i studenttexterna som exempel på den konceptuella typen som framkallades av själva restaurang-schemat utan också som exempel på anaforer av den semantiska eller inferentiella typen samt i kontexter som uttrycker ägande eller tillhörande.

Man kan konstatera att formvalet vid substantiv som antogs vara mönsterfall för det konceptuella restaurang-schemat, såsom servitören, maten eller menyn, inte var koherent och enstämmigt. Ungefär en fjärdedel av fraserna i kontexter för indirekta anaforer bedömdes som avvikande och i de flesta fall gällde det nakna substantiv, som i exempel 31 och 42.

(31) Servitören är tillbaka. Manen och kvinnan säger vad vill de ha från menu. (I4)

(42) Manen och kvinnan säger vad vill de ha från menu. Den är kvinnan som säger först. Kvinnan är mycket glad när hon ser servitören med mat. (I4)

Orsaken kan sökas i två olika problem: antingen kände studenterna inte igen kontexten för indirekt anafor eller de hade problem med formvalet. Liknande avvikelser observerades dessutom för direkta anaforer som tränas i undervisning i större utsträckning:

(22) Det finns en kvinna och en man som gick in i restaurangen. De pratar med en servitör som har ingen hår och alla är snyggklädda. [...] Servitör har något hängande på armen. (I2) 
(15) En man kommer till en restaurangen med sin fru. [...] Manen och kvinna sitter vid bordet och servitören tar han om de. (I4)

(78) De beställer mat. Först dricker de champagne och sedan får de mat. (I9)

Bortfall av den bestämda slutartikeln och underanvändning av artiklar är en tendens som observerades hos polska inlärare i tidigare forskning kring nominalfrasutveckling hos inlärare av svenska, bland annat i Erikssons och Wijk-Anderssons (1988) studie.

I Fig. 2 samlas antal och andelar kontexter för indirekta och direkta anaforer samt antal och andelar definita fraser i dessa kontexter. Dessutom presenteras antalet fraser med possessiva pronomen och antalet fraser som tolkades som avvikande överanvändning av substantiv med bestämd slutartikel.

\begin{tabular}{|c|c|c|c|c|c|c|c|c|c|c|c|}
\hline \multirow{2}{*}{ 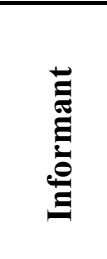 } & \multicolumn{6}{|c|}{ Indirekta anaforer } & \multicolumn{4}{|c|}{$\begin{array}{c}\begin{array}{c}\text { Direkta anaforer, } \\
\text { koreferens }\end{array} \\
\end{array}$} & \multirow[b]{2}{*}{$\begin{array}{c}\text { Antal } \\
\text { NP }\end{array}$} \\
\hline & $\stackrel{\dot{\Xi}}{\dot{\theta}}$ & $e^{0} \underset{\bar{z}}{\bar{z}}$ & $\frac{\hat{Z}}{\frac{0}{0}}$ & $e^{\ominus} \frac{\hat{z}}{\frac{\pi}{0}}$ & : & $\dot{\dot{\theta}}$ & $\dot{\vec{\Xi}}$ & 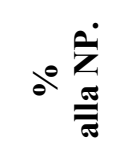 & $\frac{\hat{Z}}{0}$ & ब를 & \\
\hline I1 & 7 & $17,5 \%$ & 6 & $85,7 \%$ & 1 & 0 & 22 & $55,0 \%$ & 22 & $100,0 \%$ & 40 \\
\hline $\mathbf{I} 2$ & 7 & $15,2 \%$ & 6 & $85,7 \%$ & 0 & 1 & 20 & $43,5 \%$ & 19 & $95,0 \%$ & 46 \\
\hline $\mathbf{I 3}$ & 2 & $5,6 \%$ & 1 & $50,0 \%$ & 1 & 0 & 20 & $55,6 \%$ & 20 & $100,0 \%$ & 36 \\
\hline I4 & 5 & $13,2 \%$ & 1 & $20,0 \%$ & 0 & 0 & 22 & $57,9 \%$ & 19 & $86,4 \%$ & 38 \\
\hline $\mathbf{I 5}$ & 6 & $14,0 \%$ & 5 & $83,3 \%$ & 0 & 0 & 21 & $48,8 \%$ & 19 & $90,5 \%$ & 43 \\
\hline I6 & 3 & $8,1 \%$ & 3 & $100,0 \%$ & 0 & 1 & 14 & $37,8 \%$ & 14 & $100,0 \%$ & 37 \\
\hline $\mathbf{I 7}$ & 5 & $10,0 \%$ & 3 & $60,0 \%$ & 0 & 1 & 22 & $44,0 \%$ & 20 & $90,9 \%$ & 50 \\
\hline I8 & 8 & $15,4 \%$ & 7 & $87,5 \%$ & 0 & 3 & 26 & $50,0 \%$ & 24 & $92,3 \%$ & 52 \\
\hline I9 & 2 & $8,7 \%$ & 1 & $50,0 \%$ & 1 & 0 & 10 & $43,5 \%$ & 9 & $90,0 \%$ & 23 \\
\hline I10 & 6 & $13,3 \%$ & 5 & $83,3 \%$ & 0 & 4 & 22 & $48,9 \%$ & 21 & $95,5 \%$ & 45 \\
\hline Totalt & 51 & $12,4 \%$ & 38 & $74,5 \%$ & 3 & 10 & 199 & $48,5 \%$ & 187 & $94,0 \%$ & 410 \\
\hline
\end{tabular}

(Fig. 2) Resultat i studenttexterna

Det är påfallande att studenternas val var mest stabila i kontexter för direkt anafor och att det i studenttexterna överhuvudtaget fanns fler kontexter för direkta än indirekta anaforer. Det senare kan tolkas som påverkan av uppgiftens karaktär - bilderna beskrevs lite var för sig. Separata textdelar blev mindre sammanhängande och beskrivningen av nya bilder innebar upprepning av samma substantiv som refererade till historians karaktärer eller rum, såsom paret, kvinnan, mannen, servitören eller restaurangen. Andelen definita fraser i kontexter för direkta anaforer $(48,5 \%$ ) var markant högre än för de indirekta $(12,4 \%)$. Bland de indirekta anaforerna (11 exempel, alltså ungefär en tiondedel) 
var anaforer av den semantiska typen som gällde kroppsdelar mycket frekventa. I den gruppen förekom alla fraser som definita nominalfraser.

Fraser med possessiva pronomen som kan vara ett alternativ för fraser med bestämd slutartikel utgör nästan en tredjedel av alla definita fraser i kontexter för indirekta anaforer. De var såpass frekventa $\mathrm{i}$ informanternas produktion att andelen definita fraser skulle minska från 74,5\% till 68,8 \% om fraser med possessiva pronomen uteslöts från undersökningen och om det bara räknades fraser med substantiv med bestämdartikel.

Till och med en sådan liten studie visar att indirekta anaforer framstår som en nyanserad, oenhetlig kategori, också ur språkinlärningsperspektiv. Kontexter för användning av en definit nominalfras framstod som enklare för fraser som refererade till kroppsdelar. Kunskaper om stereotypa element, rekvisita och scenografi av vissa händelser eller platser (jfr objekt- och faktastereotyper, Maciejewski 1983:26) samt kunskapen om det konceptuella, mentala schemat hade positivt påverkan på studenternas val av fraser. En annan faktor som ter sig påverka inlärarnas beslut är relationen av tillhörande och ägande mellan triggers och anaforer. Dessa resultat sammanhänger med resultat från andra studier som genomfördes bland studenter av svenska på Institutionen för skandinavistik vid Adam Mickiewicz-universitetet i Poznań och med en kontrollgrupp av modersmålstalare av svenska (Kołaczek 2017b).

\section{LITTERATUR}

Asher, N., Lascarides, A. (1998). Bridging. Journal of Semantics 15(1), ss. 83-113.

Axelsson, M. (1994). Noun Phrase Development in Swedish as a Second Language. A study of Adult Learners Acquiring Definiteness and the Semantics and Morphology of Adjectives. Stockholm: Stockholm University Centre for Research and Bilingualism.

Bolander, M. (2001). Funktionell svensk grammatik. Stockholm: Liber.

Clark, H. H. (1983). Bridging. I: P. N. Johnson-Laird, P. C. Wason (red.), Thinking: Readings in Cognitive Science (ss. 311-326). Cambridge: Cambridge University Press.

Consten, M. (2004). Anaphorisch oder Deiktisch?: Zu einem integrativen Modell domänengebundener Referenz. Tübingen: Max Niemeyer Verlag.

Dabrowska, M. (2015). Grammatiska svårigheter hos andraspråksinlärare med polska som modersmål. Ett specialarbete publicerat i elektronisk form. Göteborg: Göteborgs Universitet. Hämtat från https://gupea.ub.gu.se/bitstream/2077/45294/1/gupea_2077_45294_1.pdf (05.11.2018).

Ekerot, L. J. (2011). Ordföljd, tempus, bestämdhet. Föreläsningar om svenska som andraspråk. Malmö: Gleerups.

Engström, S. (2012). Svårigheter $i$ inlärning av svenska som andraspråk. En C-uppsats publicerad i elektronisk form. Halmstad: Högskolan i Halmstad. Hämtat från http://hh.diva-portal.org/smash/get/diva2:478785/FULLTEXT01.pdf (05.11.2018)

Eriksson, A., Wijk-Andersson, E. (1988). Swedish Nouns and Articles in German and Polish Student's Swedish Writing. Uppsala: Uppsala Universitet.

Fraurud, K. (1990). Definiteness and the Processing of Noun Phrases in Natural Discourse. Journal of Semantics 7(4), ss. 395-433. 
Gardent, C. (et al.) (2003). Which Bridges for Bridging Definite Descriptions? 4th International Workshop on Linguistically Interpreted Corpora - LINC'03. Budapest. Hämtat från https://hal.inria.fr/inria-00107644/document (05.11.2018)

Gemensam europeisk referensram för språk: lärande, undervisning och bedömning. (2007). Stockholm: Skolverket. Hämtat från https://www.skolverket.se/publikationer?id=2144 (05.11.2018).

Hawkins, J. A. (1978). Definiteness and Indefiniteness. A Study in Reference and Grammaticality Prediction. London: Croom Helm.

Hammarberg, B. (2016). Flerspråkighet och tredjespråksinlärning. Några grundbegrepp. I: C. Bardel et al., Tredjespråksinlärning (ss. 33-58). Lund: Studentlitteratur.

Irmer, M. (2011). Bridging Inferences. Constraining and Resolving Underspecification in Discourse Interpretation. Berlin; Boston: De Gruyter.

Kołaczek N. (2017a). Jakaś książka, ten telefon i mój samochód: jak kategoria określoności przedstawiana jest w podręcznikach do języka szwedzkiego dla początkujących? I: B. Mikołajczyk et al. (red.), Język w Poznaniu 8 (ss. 17-29). Poznań: Wydawnictwo Rys.

Kołaczek, N. (2017b). Określony, czyli jaki? O pośrednim użyciu formy określonej z perspektywy uczenia się i nauczania języka szwedzkiego jako obcego. Kultura i polityka 21, ss. 32-46.

Kowal, I. (2011). Målar grammatikböcker fan på väggen? Inlärning av en "svår" kategori i svenskan. I: A. Ylikiiskilä, M. Westman (red.), Språk för framtiden/Language for the future. Rapport från ASLA:s höstsymposium, Falun, 12-13 november 2010. ASLA. (ss. 98-111).

Löbner, S. (1998). Definite Associative Anaphora. Seminar für Allgemeine Sprachwissenschaft. Düsseldorf: Heinrich-Heine-Universität. Hämtat från https://semanticsarchive.net/Archive/ mU3YzU1N/Loebner_Definite_Associative_Anaphora.pdf (05.11.2018).

Maciejewski, W. (1983). Podstawy polsko-szwedzkiej kontrastywnej lingwistyki tekstu. Uppsala: Slaviska institutionen vid Uppsala universitet; Poznań: Wydawnictwo Naukowe Uniwersytetu im. Adama Mickiewicza.

Matsui, T. (2000). Bridging and Relevance. Amsterdam: John Benjamins.

Nyqvist, E.-L. (2013a). Species och artikelbruk $i$ finskspråkiga grundskoleelevers inlärarsvenska. En longitudinell undersökning $i$ årskurserna 7-9. En doktorsavhandling publicerad i elektronisk form. Åbo: Åbo universitet. Hämtat från http://www.utupub.fi/ bitstream/handle/10024/91519/diss2013_ELNyqvist.pdf(05.11.2018).

Nyqvist, E.-L. (2013b). En vandring i djungeln kallad species. Språkbruk 4/2013. Hämtat från http://www.sprakbruk.fi/index.php?mid=2\&pid=13\&aid=4158 (05.11.2018)

Nyqvist, E.-L. (2016). Swedish as a L3 for Finnish learners: The role of complexity and crosslinguistic influence in the case of definiteness and the use of articles. Research in Language 14(3), ss. 297-327.

Orientación Andújar. Recursos Educativos (u.å) Hämtat från http://www.orientacionandujar.es/ wp-content/uploads/2013/12/coleccion-secuencias-temporales-3-vinetas.pdf (20.03.2018).

Poesio, M., Vieira, R. (1998). A Corpus-based Investigation of Definite Description Use. Computational Linguistics 24(2), ss. 183-216.

Prince, E. F. (1981). Toward a Taxonomy of Given-New Information. I: P. Cole (red.), Radical Pragmatics (ss. 223-256). New York: Academic Press.

SAG 3 = Telemann, U., Hellberg, S., \& Andersson, E. (1999). Svenska Akademis Grammatik. Del 3: Fraser. Stockholm: Nordstedts Ordbok.

Schwarz, M. (2000). Indirekte Anaphern in Texten: Studien zur domänengebundenen Referenz und Kohärenz im Deutschen. Tübingen: Max Niemeyer.

Schwarz-Friesel, M. (2007). Indirect Anaphora in Text. A Cognitive Account. I: M. SchwarzFriesel, et al. (red.), Anaphors in Text: Cognitive, Formal and Applied Approaches to Anaphoric Reference (ss. 3-20). Amsterdam; Philadelphia: John Benjamins.

Szulc, A. (1992). Gramatyka dydaktyczna języka szwedzkiego. Kraków: Uniwersytet Jagielloński. Wydział Filologiczny. Instytut Filologii Germańskiej. 
Svartholm, K. (1978). Svenskans artikelsystem: en genomgång av artikelbruket $i$ vuxenspråket och modell för analys av bruket $i$ barnspråket. Stockholm: Stockholms universitet. Institutionen för nordiska språk.

Zhao, W. (2014). A Survey of Studies of Bridging Anaphora. Canadian Social Science 10(3), ss. $130-139$.

\section{Natalia Kołaczek}

Uniwersytet im. Adama Mickiewicza w Poznaniu

Katedra Skandynawistyki

Collegium Novum

al. Niepodległości 4

61-874 Poznań

Poland

natalia.kolaczek@amu.edu.pl 